\title{
Variable retention in Tasmania, Australia: trends over 16 years of monitoring and adaptive management
}

\author{
Robyn E. Scott ${ }^{1 *}$ D, Mark G. Neyland ${ }^{2}$ and Susan C. Baker ${ }^{2}$
}

\begin{abstract}
Background: Variable retention harvesting using aggregated retention (ARN) has been applied in some Tasmanian wet eucalypt forests for $>15$ years. Implementation of ARN in Tasmania differs from most other regions, as forest influence (or the proximity of harvested areas to long-term retention) is primarily used to distinguish ARN from clearfelling rather than retention level, and broadcast burning is used as a regeneration treatment, resulting in a preference for edge aggregates instead of isolated retained islands. Clear emphasis on site-level retention of biological legacies and forest influence to facilitate re-establishment of mature forest species ensures that ARN coupes achieve the ecological objectives associated with retention forestry.

Results: Spatial and survey data collected from operational ARN coupes illustrates the development of this silvicultural practice over time and allows comparisons with conventional clearfelling. Over $90 \%$ of ARN coupes have met the forest influence target of $>50 \%$. The number of ARN coupes harvested per year has varied, but mean retention levels (29\%) and the mean area harvested per coupe (24 ha) have remained the same. Forest influence in ARN coupes has decreased over time, as have perimeter-to-area ratios, largely due to a decrease in the number of island aggregates. Although these measures of complexity have decreased, ARN coupes still have much greater forest influence, retention, and perimeter-to-area ratios when compared to conventional clearfell, burn and sow (CBS) coupes. The observed decrease in boundary complexity should facilitate regeneration burning in ARN coupes, although no increase in the proportion of burnt seedbed was observed. The proportion of burnt seedbed is strongly correlated with eucalypt seedling stocking and density in ARN coupes, and these attributes were all significantly lower in recent ARN coupes compared to clearfells. These differences appear to be due to achieving better burns in recent CBS coupes, rather than poorer ones in ARN coupes.
\end{abstract}

Conclusions: Although the area that can feasibly be harvested by ARN is limited by the requirement for regeneration burning, ARN provides clear biodiversity benefits and satisfactory silvicultural outcomes and is now firmly embedded as a viable alternative to clearfelling in Tasmanian wet eucalypt forests.

Keywords: Retention forestry, Silviculture systems, Aggregated retention, Regeneration burning, Regeneration success, Forest influence, Eucalyptus

\footnotetext{
*Correspondence: robyn.scott@sttas.com.au

'Sustainable Timber Tasmania, 99 Bathurst St, Hobart, Tasmania 7001,

Australia

Full list of author information is available at the end of the article
} 


\section{Introduction}

Variable retention (VR) is an alternative approach to forest harvesting in which part of the original forest is retained after harvest and through the next rotation to better emulate natural disturbance regimes and protect biodiversity (Franklin et al. 1997; Mitchell and Beese 2002). Also known as retention forestry or green-tree retention, variable retention aims to maintain mature forest species and structures in the managed forest landscape, improve landscape connectivity, and decrease the time required for late-successional species to re-establish in harvested areas (Franklin et al. 1997). Retention can be dispersed, with single trees or small clumps of trees left throughout the coupe (as cutblocks or stands are known in Australia), or aggregated, with groups or patches of trees retained. Variable retention is a flexible approach that can be implemented using a number of different silvicultural systems and is now widely used in temperate and boreal forests worldwide (Gustafsson et al. 2012; Lindenmayer et al. 2012). A large body of scientific research has demonstrated the ecological benefits of this approach (Rosenvald and Lõhmus 2008; Fedrowitz et al. 2014; Mori and Kitagawa 2014).

In Tasmania, Australia, as in other parts of the world, social pressure against clearfelling (clearcutting) in old-growth forests led to a search for alternative harvesting methods, which prompted the establishment of the Warra Silvicultural Systems Trial in the 1990s (Baker and Read 2011; Neyland et al. 2012). Based on the results of this trial and an extensive review of alternative harvesting methods applied internationally, aggregated retention (ARN) was recommended for use in Tasmania's tall wet eucalypt forests because it provides the best balance of outcomes for biodiversity, safety, social acceptability, productivity, economics, and silviculture when compared to other alternative silvicultural systems (Forestry Tasmania 2009a; Baker and Read 2011; Neyland et al. 2012).

A key challenge in implementing variable retention silviculture in wet eucalypt forests was the need to develop effective burning methods to allow reliable regeneration from aerially sown seed (Forestry Tasmania 2009a; Scott et al. 2012b). Harvesting in these forests results in heavy slash loads which must be removed to allow eucalypt regeneration to establish (Forestry Tasmania 2009b). This is usually achieved via a high-intensity burn, which provides ideal seedbed conditions for germination and establishment of eucalypt seedlings (Neyland et al. 2009; Scott et al. 2013). Regeneration burning relies on mineral earth firebreaks established around the edges of the coupe, a helicopter-mounted drip-torch for lighting, and the resulting convection column to draw the fire away from the forested edges, reducing the risk of escapes into the adjacent unharvested forest (Forestry Tasmania 2005). In an aggregated retention coupe with irregular edge shapes and retained island aggregates, this type of burning cannot be used. Thus, a new burning prescription (slow burning), which aims to minimize convection while still ensuring fine fuels are burnt, was developed specifically for ARN coupes (Chuter 2007; Scott et al. 2012b).

Sustainable Timber Tasmania (STT) (formerly known as Forestry Tasmania) is a government business enterprise tasked with managing all public timber production land in Tasmania (Sustainable Timber Tasmania 2018). The first ARN harvesting by STT occurred in 2003 (Forestry Tasmania 2009a), and the system continues to be used today, along with conventional silvicultural methods such as clearfell, burn and sow (CBS) and various types of partial harvesting (Forestry Tasmania 2010). Aggregated retention is currently recommended for coupes in wet eucalypt forest containing greater than $25 \%$ by area mapped old-growth forest or with high landscape-level conservation values and may also be used in areas containing special values that must be protected (Scott and Baker 2018). Sustainable Timber Tasmania's main goals for variable retention silviculture are ecological and were developed specifically for wet eucalypt forests: aggregated retention coupes aim to better emulate ecological processes at the scale of the harvested coupe by retaining late-successional species and structures for the long term and by maintaining forest influence to facilitate re-establishment of organisms back into the harvested areas (Baker and Read 2011; Scott and Baker 2018). The concept of forest influence is used to distinguish Tasmanian aggregated retention coupes from clearfells, with the requirement that the majority of the harvested area in an aggregated retention coupe must fall within one tree height of forest that is retained for the long term (Mitchell and Beese 2002; Baker et al. 2013b, 2017; Scott and Baker 2018) (Fig. 1). This differs from variable retention harvesting in most other regions, wherein a minimum level of retention is usually prescribed (Gustafsson et al. 2012).

Tasmania has among the highest levels of forest reservation in the world, with $58 \%$ of its native forests protected in either formal or informal reserves (FPA 2017). In some instances where there is enough long-term retention immediately adjacent to harvested areas, these reserved areas may allow the goals of variable retention to be met with little or no additional coupe-level retention (Fig. 1b). Where extra retention is needed, it is left either as island aggregates (free-standing patches within the harvested area) or as edge aggregates, contiguous with the coupe boundary (Fig. 1a). Edge aggregates provide greater connectivity with the surrounding forest (Baker et al. 2017) and have proven to be less susceptible than islands to damage from the regeneration burn and windthrow (Scott et al. 2012b, 2015). When island aggregates are retained, they are generally large ( $>1$ ha is recommended) to ensure they will withstand the regeneration burn (Scott and Baker 2018). 

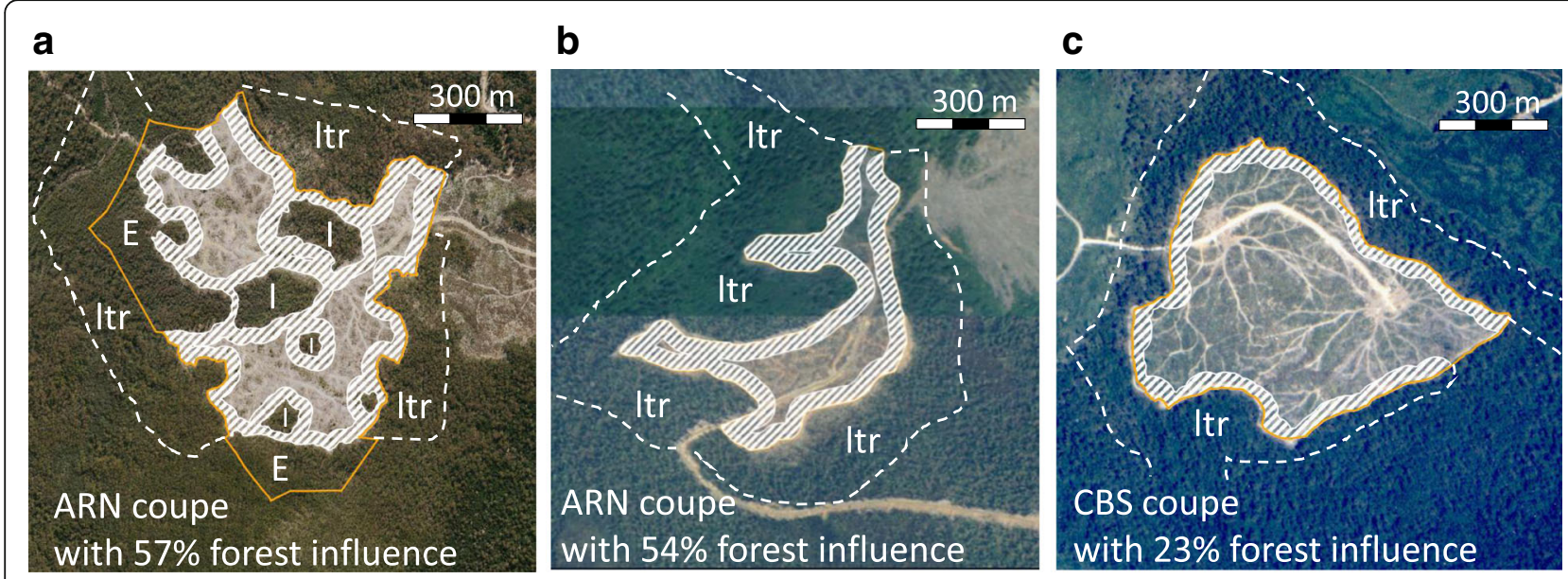

Fig. 1 An overhead aerial view of two aggregated retention (ARN) coupes (a, b) and a clearfell, burn and sow (CBS) coupe (c), showing the area under forest influence. The yellow line indicates the coupe boundary (i.e., the area available for harvest), while the diagonal lines show the portion of the harvested area within one tree height of retained standing forest. Also marked are edge aggregates (E), island aggregates (I), and long-term retention outside of the coupe (Itr, delineated by dashed lines). The ARN coupe in a has 44\% retention in edge and island aggregates within the coupe boundary, while the ARN coupe in $\mathbf{b}$ has $0 \%$ retention within the coupe because conservation objectives are achieved by the long-term retention outside the coupe

The difference between aggregates (retained inside a coupe) and long-term retention outside of a coupe relates to the availability of those areas for timber production and flexibility of zoning for the future. Retained aggregates remain within the coupe boundary, consist mainly of foregone merchantable timber, and are potentially available for harvest in future rotations if there is a biological rationale to move the locations of aggregates. All aggregates are identified with a "special management zone" and mapped in the GIS-based Management Decision Classification system which is used to zone land and record identified special values and their management requirements (Sustainable Timber Tasmania 2018).

As part of a government-funded program of research into alternatives to clearfelling in Tasmania, operational monitoring and research programs focusing on silviculture and biodiversity were put into place (Forestry Tasmania 2009a). The silviculture research program collected data from 38 ARN and 31 clearfell, burn and sow (CBS) coupes harvested from 2003 to 2009 and regenerated from 2007 to 2010. Coupes were intensively monitored for up to 3 years to provide data on coupe sizes and shapes, retention and influence levels, the presence of seed trees and seed crop scores, the width and extent of firebreaks, harvesting damage and windthrow, burning conditions, seedbed, burn damage, and early eucalypt regeneration (Scott et al. 2012a, 2012b, 2013, 2015). The results from the biodiversity research program revealed that aggregates are effective for providing habitat for plants and animals within coupes and also play a role in facilitating their re-establishment into harvested areas (Stephens et al. 2012; Baker et al. 2013a, 2016; Fountain-Jones et al. 2015).
The results of this early research were used to inform the development of ARN silviculture through a process of adaptive management (Baker et al. 2017). Changes in firebreaking methods helped to reduce the level of soil disturbance and site preparation costs in ARN coupes (Scott et al. 2012b). The development of effective "slow burning" methods, the adoption of aerial sowing as standard practice rather than relying on seed sources in aggregates and nearby unlogged forest, and changes in coupe design including the use of fewer and larger aggregates all served to reduce the impact of burn escapes and create adequate levels of receptive seedbed (Scott et al. 2012b) with the result that the height growth and density of regeneration established in the ARN coupes up to 3 years of age were very similar to that in comparable CBS coupes (Scott et al. 2013).

Since 2009, a number of additional ARN coupes have been harvested around Tasmania. No formal monitoring has been carried out in these recent coupes apart from that required for organizational reporting, but the collection of operational and spatial data is ongoing through STT's Forest Operations Database and Geographic Information Systems (GIS). This paper summarizes the spatial attributes and available operational survey data collected to date in Tasmanian ARN coupes and in a subset of paired clearfell, burn and sow (CBS) coupes, to review forest influence and retention levels, coupe size and shape, aggregate size, shape and number, burning outcomes (seedbed), and regeneration success. It aims to determine whether ARN coupes are meeting the targets for forest influence and other silvicultural objectives, to compare the outcomes in recent ARN and CBS coupes, 
and to highlight any trends or changes in coupe design or outcomes that have occurred over the past 16 years. Most of the international research reported on variable retention has been derived from silvicultural systems trials such as Warra (Neyland et al. 2012), DEMO (Aubry et al. 2009), and EMEND (Work et al. 2004). While useful, research trials are not always representative of operational practices. The information presented here from $>100$ operational coupes provides an unusual opportunity to analyze how an emerging silvicultural system has been implemented in practice.

\section{Methods}

\section{Study area}

Coupes were distributed across Tasmania, Australia, and were mainly located in tall wet eucalypt forests. These highly productive forests occur in areas of moderate to high rainfall and are characterized by a tall eucalypt overstory over a dense understory layer of shrubs and small trees (Wells and Hickey 1999). Coupes ranged in altitude from 50 to 1000 masl, while annual rainfall ranged from 850 to $2100 \mathrm{~mm} /$ year. Most coupes were harvested using ground-based methods, although some were partially cable-harvested. Coupes were burnt for regeneration in the autumn and aerially sown with locally collected eucalypt seed after burning.

\section{Data collection}

This paper summarizes the available research and operational survey data collected to date in 115 Tasmanian ARN coupes and a set of 80 paired clearfell, burn and sow (CBS) coupes. Previously collected research data from 38 ARN and 31 paired CBS coupes harvested from 2003 to 2009 and described in detail in Scott et al. (2012a, 2012b, 2013, 2015) was supplemented by operational and GIS-based survey data from an additional 77 ARN and 49 paired CBS coupes.

A list of harvested coupes was obtained from Sustainable Timber Tasmania's operations database and GIS. All ARN coupes harvested from 2003 to 2018 with completed operations and updated mapping were selected $(n=115)$. For those analyses that compare the outcomes in recent ARN and CBS coupes, only ARN coupes harvested from 2010 were considered, and a nearby CBS coupe burnt or harvested in the same year was matched to each ARN coupe where possible. A total of 49 recent ARN/CBS pairs were identified. This enables an analysis of shifts in implementation and outcomes over a 16-year time frame.

The following attributes were calculated or obtained for all coupes, where possible. Due to the nature of operational survey data and changes in the management status of some coupes over time, not all records were complete. Harvested area (ha), perimeter length of the harvested area $(\mathrm{m})$, the number and type of aggregates (edge or island), and individual aggregate areas (ha) for each coupe were obtained from map layers in the GIS. Perimeter-to-area ratios $\left(\mathrm{m} \mathrm{ha}^{-1}\right)$ were calculated for each coupe by dividing the perimeter length by the harvested area. Coupe areas were adjusted after harvest to reflect the actual rather than planned harvest shapes, and in the case of ARN coupes, to identify retained aggregates. These updates depend on the availability of aerial photos and often are not completed until 1-2 years after the harvest; hence, data were not available for all coupes. Coupe areas (ha) were obtained for all coupes where post-harvest mapping updates had been completed. The calculation of retention levels also depends on an updated post-harvest mapping, and retention level (\%) in each coupe was calculated as:

$$
(\Sigma(\text { aggregate area }) /(\text { harvested area }+\Sigma(\text { aggregate area }))) \times 100
$$

Forest influence for each coupe was calculated as the proportion of the harvested area within one tree height of retained native forest, using a custom-built software tool running in MapInfo (Scott 2008). The tree height used was the mean dominant height of the aggregates and surrounding forest calculated from photo-interpreted stand types (Stone 1998). Retention and influence calculations provide only a snapshot of the coupe at a moment in time, and do not account for any windthrow or burning damage that may have occurred within the aggregates after harvesting, although monitoring in early ARN coupes revealed that these were generally within acceptable limits (Scott et al. 2012b; Baker et al. 2017).

Data on seedbed and eucalypt seedling regeneration were obtained from Sustainable Timber Tasmania databases and were based on standard regeneration surveys (Forestry Tasmania 2012). These systematic surveys with a random starting point assess regeneration stocking (presence of at least one acceptable eucalypt seedling) and the number of eucalypt seedlings, in $16 \mathrm{~m}^{2}$ plots located every $20 \mathrm{~m}$ along lines $100 \mathrm{~m}$ apart, with a minimum of 50 plots per coupe. Seedbed under the tallest dominant seedling (or the dominant seedbed on the majority of the plot if no seedling is present) was also assessed and classified as either burnt, disturbed by harvesting machinery, or unburnt/undisturbed (Forestry Tasmania 2012). The proportion of the sample points falling into each seedbed class was calculated for each coupe. In wet eucalypt forests, both burnt and disturbed seedbeds are considered to be receptive, with the best growth and greatest density of seedlings usually occurring on well-burnt seedbeds (King and Cook 1992; Neyland et al. 2009). Age 1 stocking (\%) was calculated as the percentage of plots containing at least one acceptable seedling, while age 1 density is the average density of eucalypt seedlings across all plots in stems per hectare (sph). 
Table 1 Summary statistics for selected attributes of ARN coupes harvested since 2003

\begin{tabular}{llllll}
\hline Attribute & Mean & sd & Number & Min & Max \\
\hline Coupe area (ha) & 38.6 & 25.3 & 89 & 4.7 & 139.2 \\
Harvest area (ha) & 24.3 & 13.8 & 115 & 3.6 & 74.4 \\
Perimeter length (m) & 4728 & 2313 & 115 & 773 & 11,662 \\
Perimeter-to-area ratio $\left(\mathrm{m} \mathrm{ha}^{-1}\right)$ & 210 & 71 & 115 & 117 & 543 \\
Influence (\%) & 68 & 14 & 115 & 34 & 97 \\
Retention (\%) & 29 & 20 & 89 & 0 & 75 \\
Burnt seedbed (\%) & 64 & 24 & 82 & 0 & 100 \\
Disturbed seedbed (\%) & 26 & 20 & 82 & 0 & 93 \\
Unburnt/undisturbed seedbed (\%) & 10 & 15 & 82 & 0 & 1 \\
Age 1 stocking (\%) & 70 & 17 & 80 & 26 & 100 \\
Age 1 density (\%) & 2507 & 1724 & 78 & 348 & 9500 \\
\hline
\end{tabular}

Number varies due to incomplete survey records or unfinished post-harvest mapping updates for some coupes. Also given are the mean, standard deviation (sd), and minimum ( $\mathrm{min}$ ) and maximum (max) value

\section{Data analysis}

Spearman correlations were used to examine the relationships between variables, while graphical analysis and the Shapiro-Wilks test were used to check data distributions and identify outliers. Generalized additive models (GAMs) were used to identify significant trends in response variables over time using the "mgcv" package in R (Wood 2017). This approach allows non-linear patterns in the response variables to be described. Paired $t$ tests and the Wilcoxon paired signed-ranks test were used to test the differences between the ARN and CBS silvicultural systems. Analyses and mapping were completed in ArcGIS, MapInfo, and R software (R Core Development Team 2018).

\section{Results}

How many VR coupes have been harvested in Tasmania?

Since the start of VR harvesting in 2003, a total of 115 ARN coupes have been harvested, with an average of $7.2 \pm 4.8$ (average \pm standard deviation) coupes or $175 \pm$ 128 ha harvested per year. The mean harvested area across all ARN coupes was 24.3 ha (Table 1), and this did not change significantly over time $\left(d^{2}=0.004, p=\right.$ 0.562 ). The number of ARN coupes harvested has varied over time, with a peak from 2009 to 2013 (Fig. 2).

\section{Have we met the forest influence target?}

Overall, 93\% of ARN coupes have met the target of at least $50 \%$ forest influence, with an average of $68 \%$ of the harvested area being within one tree height of long-term retention (Table 1). There are eight coupes which did not meet the $50 \%$ forest influence target. Of these, five had between 45 and $49 \%$ forest influence and only three had less than $45 \%$ forest influence over the harvested areas.

\section{How did forest influence and retention change over time?} Forest influence in ARN coupes has decreased in a non-linear fashion over time (Fig. 3a), as has perimeter-to-area ratio (Fig. 3b). While significant, the relationships with time were rather weak (\% deviance explained was $\leq 17 \%)$.

Final coupe areas were available for 89 of the 115 ARN coupes and ranged from 5 to 139 ha (mean $=38.7 \pm 25.5$ ha), while harvest areas ranged from 3.6 to 74.4 ha.

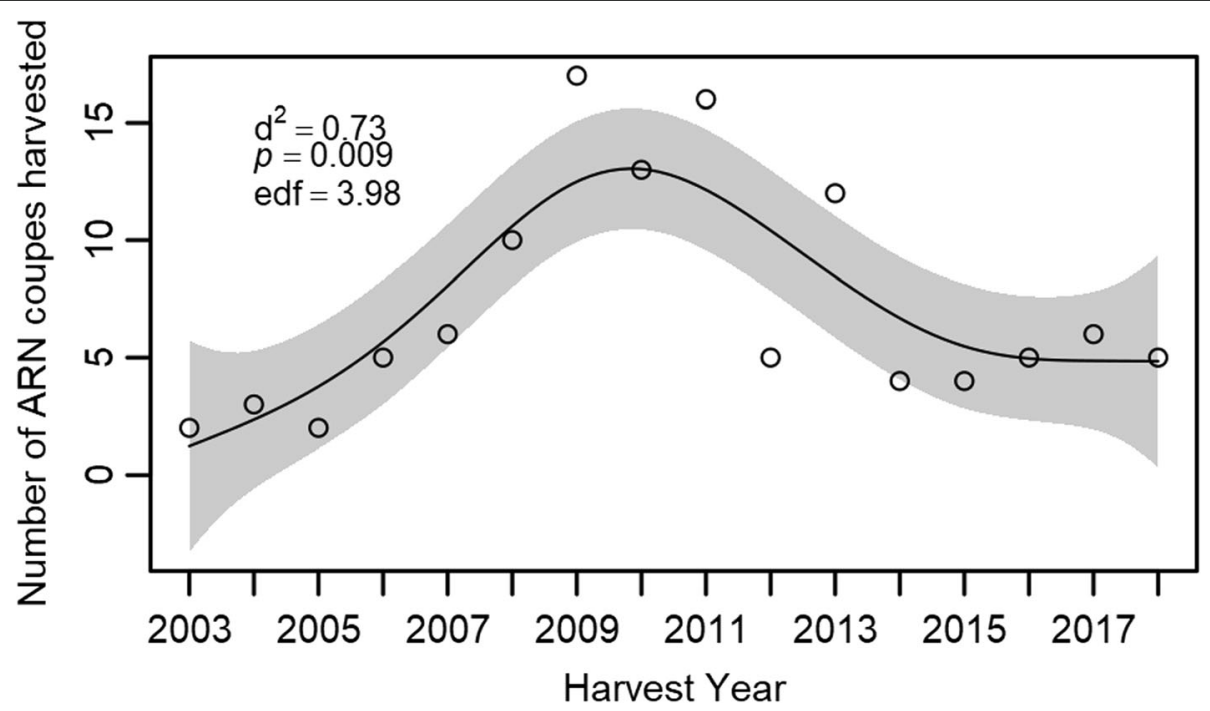

Fig. 2 Generalized additive model of the relationship between harvest year and the number of ARN coupes harvested. Shaded areas indicate the $95 \%$ confidence interval. $d^{2}$ is the proportion of the null deviance explained by the model. $p$ values indicate the approximate significance of the single smooth term, while edf is the estimated degrees of freedom for the smooth term 

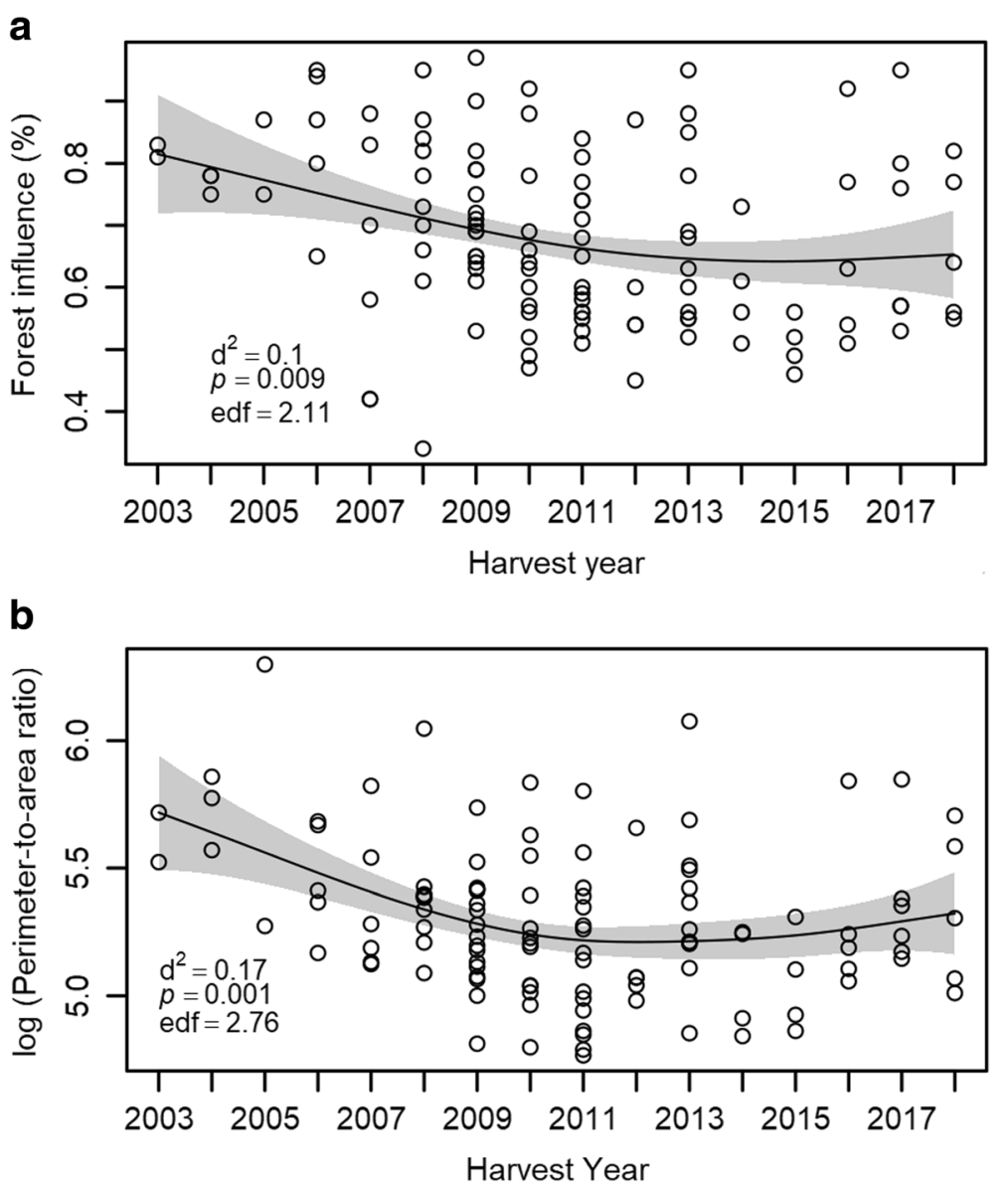

Fig. 3 Generalized additive models of the relationship between harvest year and $\mathbf{a}$ forest influence and $\mathbf{b}$ perimeter-to-area ratio in ARN coupes. Shaded areas indicate the $95 \%$ confidence interval. Perimeter-to-area ratio was log-transformed prior to modelling. $d^{2}$ is the proportion of the null deviance explained by the model. $p$ values indicate the approximate significance of the single smooth term, while edf is the estimated degrees of freedom for the smooth term

Retention level has not changed significantly over time (Fig. 4) with an average of $29 \pm 20 \%$ or $14.0 \pm 14.8$ ha retained.

Although mean retention levels have been stable, the type and number of aggregates retained in coupes have changed considerably (Figs. 5 and 6). A total of 16 ARN coupes were planned with no internal retention (retention $=0 \%$; ; these were evenly distributed, with at least one coupe of this sort harvested in most years. For these coupes, coupe boundary configuration with long-term retention immediately adjacent to the coupes was relied upon to meet the forest influence target and other ecological objectives (i.e., Fig. 1b). A total of 460 retained aggregates were mapped in 107 ARN coupes, with an average of $4.3 \pm 4.0$ aggregates per coupe. The number of island aggregates retained per coupe ranges from 0 to 11 and has remained quite low in the past 10 years except in a few coupes (Fig. 5). In recent years, the mean number of island aggregates per coupe has been less than 1 (Fig. 5).
There has been a decrease in the number and total area of island aggregates and conversely an increase in the number and total area of edge aggregates over time. Although $54 \%$ of the total number of aggregates are edge aggregates, they account for $80 \%$ of the total aggregate area (Fig. 6). The mean size of aggregates across all ARN coupes is $1.4 \pm 1.3$ ha for islands and $4.8 \pm 8.1$ ha for edges.

\section{Seedbed and regeneration}

Seedbed and regeneration survey results were available for 79 ARN coupes at age 1 year. On average, $64 \%$ of the harvested area of ARN coupes was burnt, $26 \%$ disturbed, and $10 \%$ unburnt/undisturbed, but these proportions varied considerably from coupe to coupe. The amount of burnt seedbed did not vary significantly with year burnt $\left(d^{2}=\right.$ $0.025, p=0.301$ ). The mean density of eucalypt seedlings in ARN coupes at age 1 year was $2507 \mathrm{sph}$, while the proportion of stocked $16 \mathrm{~m}^{2}$ plots averaged $70 \%$ (Table 1). The standard for regeneration in ARN coupes is that at least 


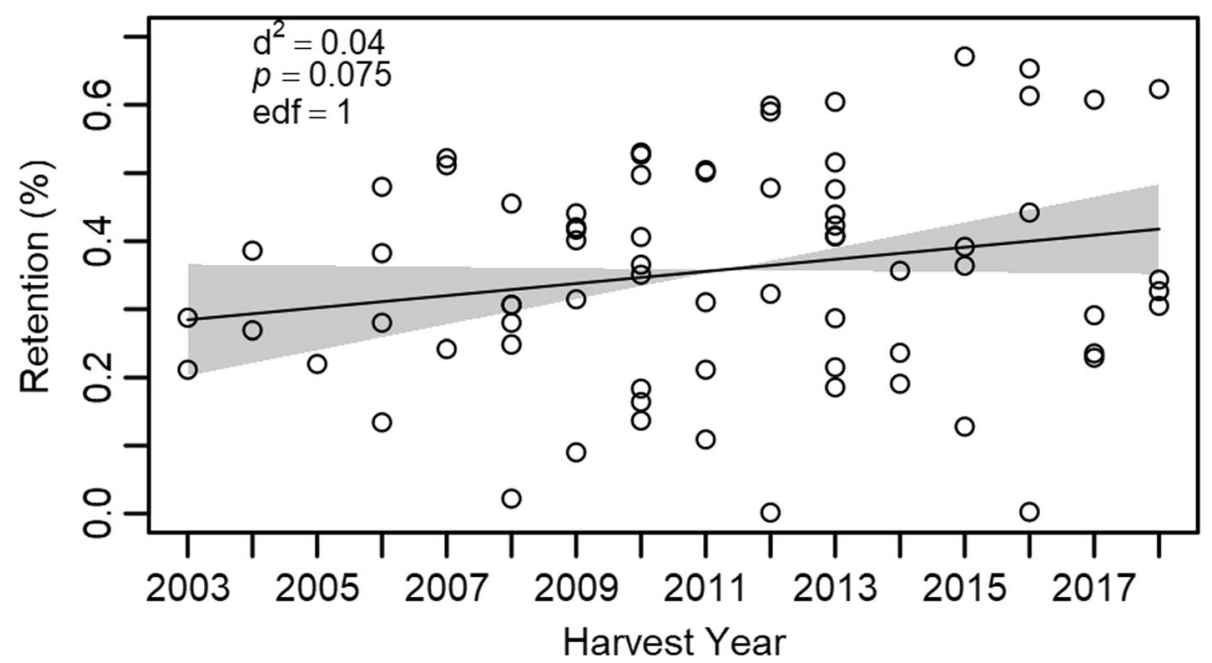

Fig. 4 Generalized additive model of the relationship between harvest year and retention level for coupes with retention $>0(n=73)$. The model has simplified to a linear model (edf $=1)$, but the relationship is not significant $(p=0.075)$. Shaded areas indicate the $95 \%$ confidence interval. $d^{2}$ is the proportion of the null deviance explained by the model. $p$ values indicate the approximate significance of the single smooth term, while edf is the estimated degrees of freedom for the smooth term

$65 \%$ of plots should be stocked by 3 years of age. Twenty-six ARN coupes (33\%) were understocked at age 1 year, and of these, eight coupes (7\%) remained understocked at age 3 years.

Seedling density varied with year burnt (Fig. 7a) and increased linearly as burnt seedbed increased (Fig. 7b). Seedling stocking also increased linearly with burnt seedbed (Fig. 8) but did not vary with year burnt (not shown).

\section{Differences between silvicultural systems}

Perimeter lengths were greater, and harvested areas were smaller in recent ARN coupes compared to paired clearfells, leading to much larger perimeter-to-area ratios for coupes harvested from 2010 to 2018 (Table 2). This is very similar to the results from earlier coupes (Table 3), although the difference between ARN and CBS coupes is less in recent coupes.

Forest influence was significantly greater in recent ARN coupes than in comparable clearfells (Table 2), although the difference was less than in early coupes $(31 \%$ vs $41 \%$, Table 3 ). Retention levels also were significantly higher in ARN coupes (Table 2).

Seedbed and regeneration survey data was available for 36 of the 49 ARN/CBS pairs. The proportion of coupe harvested area consisting of burnt seedbed was significantly

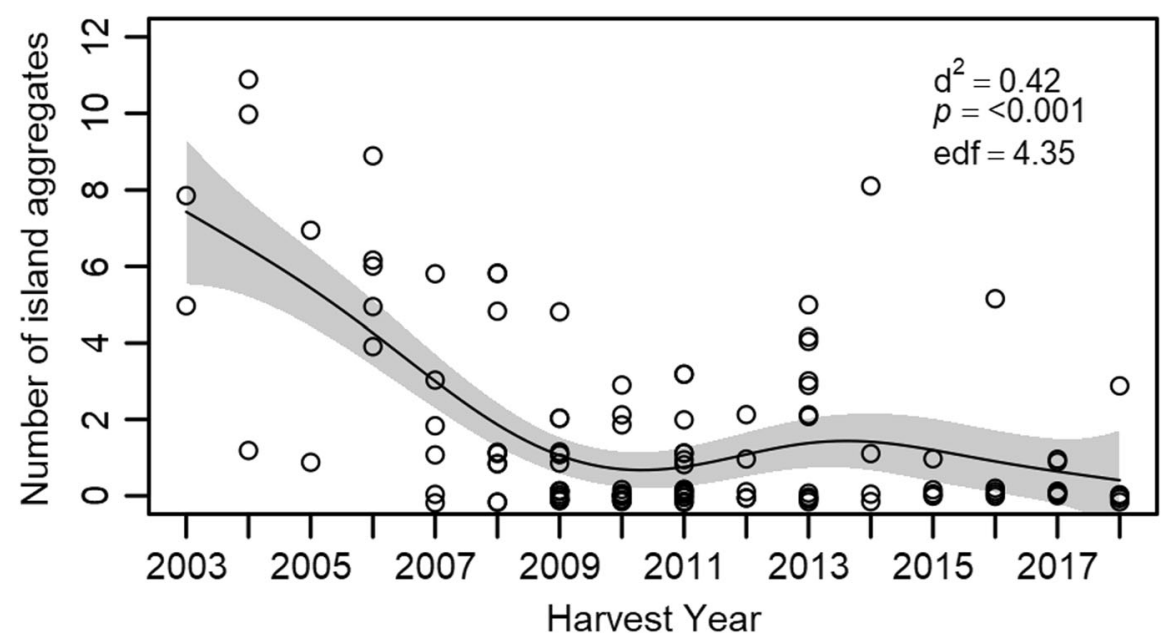

Fig. 5 Results of generalized additive model for evaluating the patterns in number of island aggregates in ARN coupes $(n=115)$. Shaded areas indicate the $95 \%$ confidence interval. Symbols are partial residuals around the predicted effects. $d^{2}$ is the proportion of the null deviance explained by the model. $p$ values indicate the approximate significance of the single smooth term, while edf is the estimated degrees of freedom for the smooth term 


\section{a}

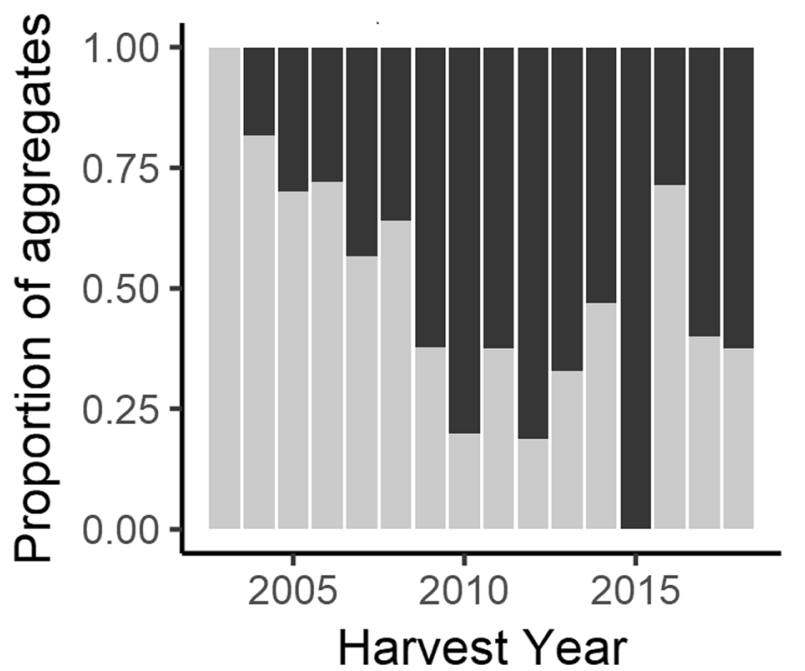

\section{TYPE EDGE ISL}

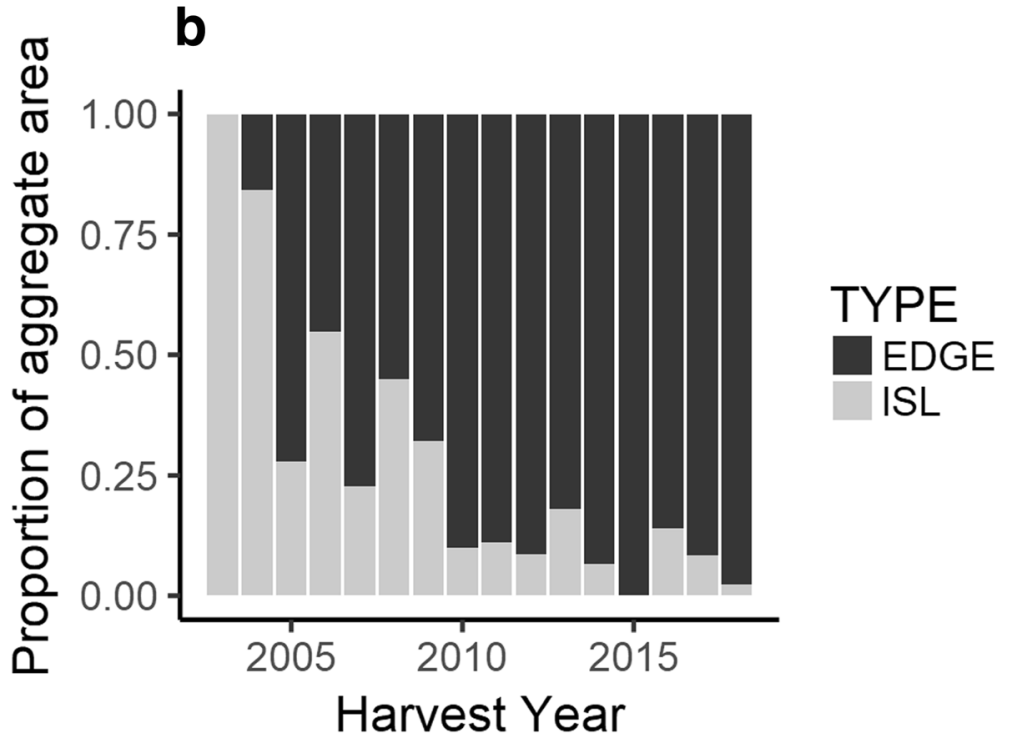

Fig. $\mathbf{6}$ Proportion of $\mathbf{a}$ total number of aggregates and $\mathbf{b}$ total aggregate area by aggregate type over time in ARN coupes

lower in recent ARN coupes compared to clearfells (63\% vs $79 \%$, mean difference $=-17 \%, n=36, p<0.0001$, Table 2). There was a similar trend in earlier coupes, but the difference was less pronounced (63\% vs $68 \%$, Table 3 ).

In the recent paired coupes, both regeneration stocking and density were significantly lower in ARN than in CBS coupes at 1 year of age (Table 2). This contrasts with coupes harvested before 2010 for which there were no significant differences in eucalypt regeneration stocking or density between ARN and paired CBS coupes 1 year of age (Table 3).

\section{Discussion}

Aggregated retention (ARN) harvesting in Tasmania has changed over 16 years of implementing the system as an alternative to clearfelling. Over $90 \%$ of ARN coupes have met the target of $>50 \%$ forest influence, with average forest influence of $68 \%$. The number of coupes harvested per year has varied, while the mean area harvested and retention levels have remained the same. ARN coupes are being designed with fewer island aggregates and more edge aggregates, leading to reduced perimeter-to-area ratios. These changes should facilitate regeneration burning, although no increase in the proportion of burnt seedbed was observed. Although mean forest influence levels have decreased, ARN coupes have twice as much forest influence as comparable clearfells. Burnt seedbed is strongly correlated with eucalypt seedling stocking and density in ARN coupes, and the proportion of burnt seedbed, as well as regeneration stocking and density at age 1, 

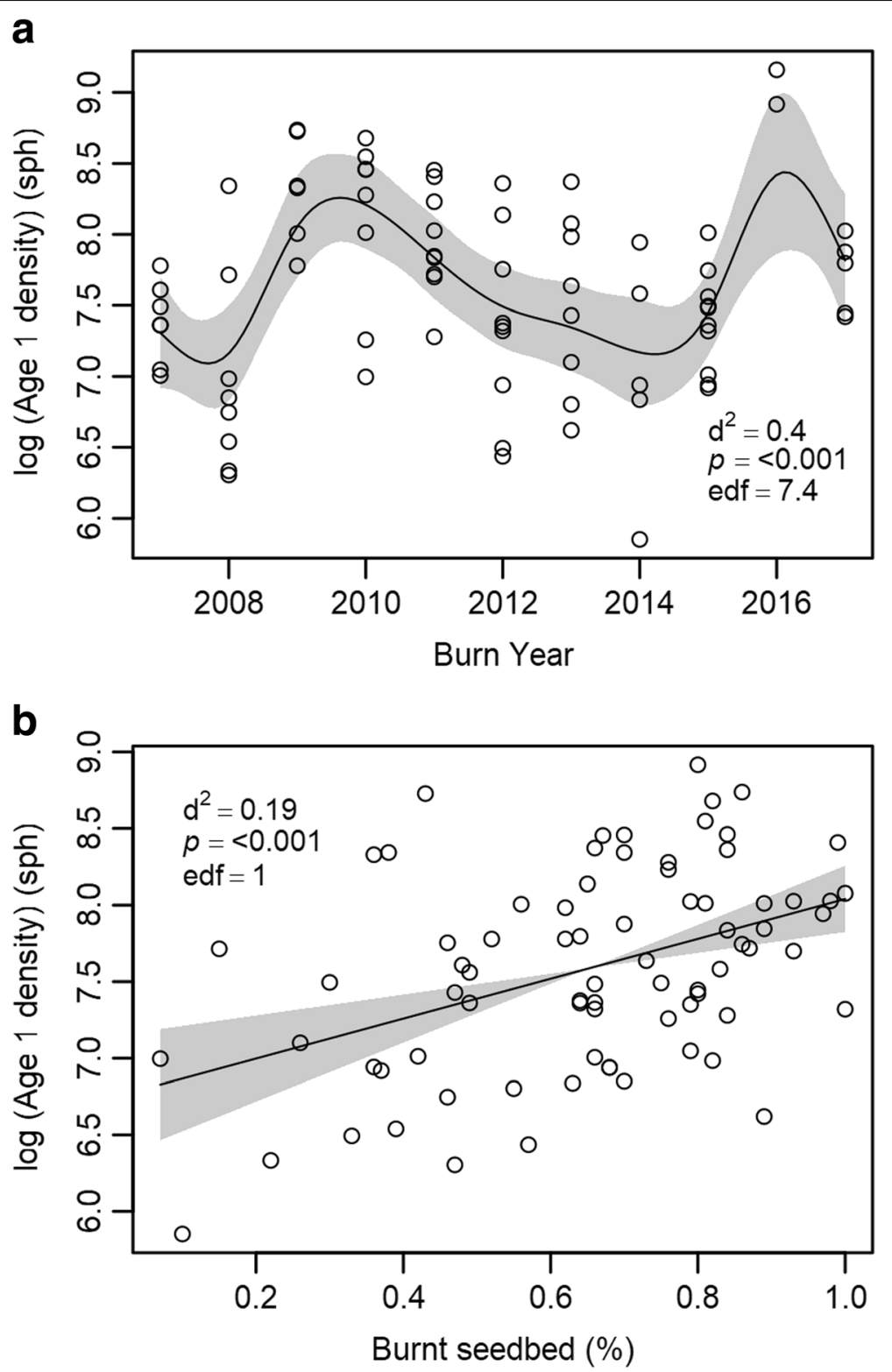

Fig. 7 Results of generalized additive models of the relationship between eucalypt density at age 1 year with a year burnt and $\mathbf{b}$ burnt seedbed in ARN coupes $(n=76)$. Shaded areas indicate the $95 \%$ confidence interval. Density was log-transformed prior to modeling. $d^{2}$ is the proportion of the null deviance explained by the model. $p$ values indicate the approximate significance of the single smooth term, while edf is the estimated degrees of freedom for the smooth term

were all significantly lower in recent ARN coupes compared to clearfells.

The implementation of ARN harvesting has occurred during a time of great change in Tasmanian forestry. In the 16 years since ARN harvesting began, the area of public forests managed for timber production in Tasmania has declined by $45 \%$ as large areas, including most old-growth forest, were added to reserves (Schirmer et al. 2018). Consequently, the number of people employed in forestry declined by more than $50 \%$, and there were a number of significant changes to forest legislation and policy, including a drop in the production target for high-quality sawlog from public land from $300,000 \mathrm{~m}^{3} /$ year to $137,000 \mathrm{~m}^{3} /$ year (Schirmer et al. 2018; Sustainable Timber Tasmania 2018). The number of ARN coupes harvested showed a peak across 2009-2013 and varied from year to year. These changes reflect the operational realities of forest harvesting as well as the decline in the area of public forest managed for timber production due to increased forest protection. ARN currently makes up approximately $4 \%$ of the annual 


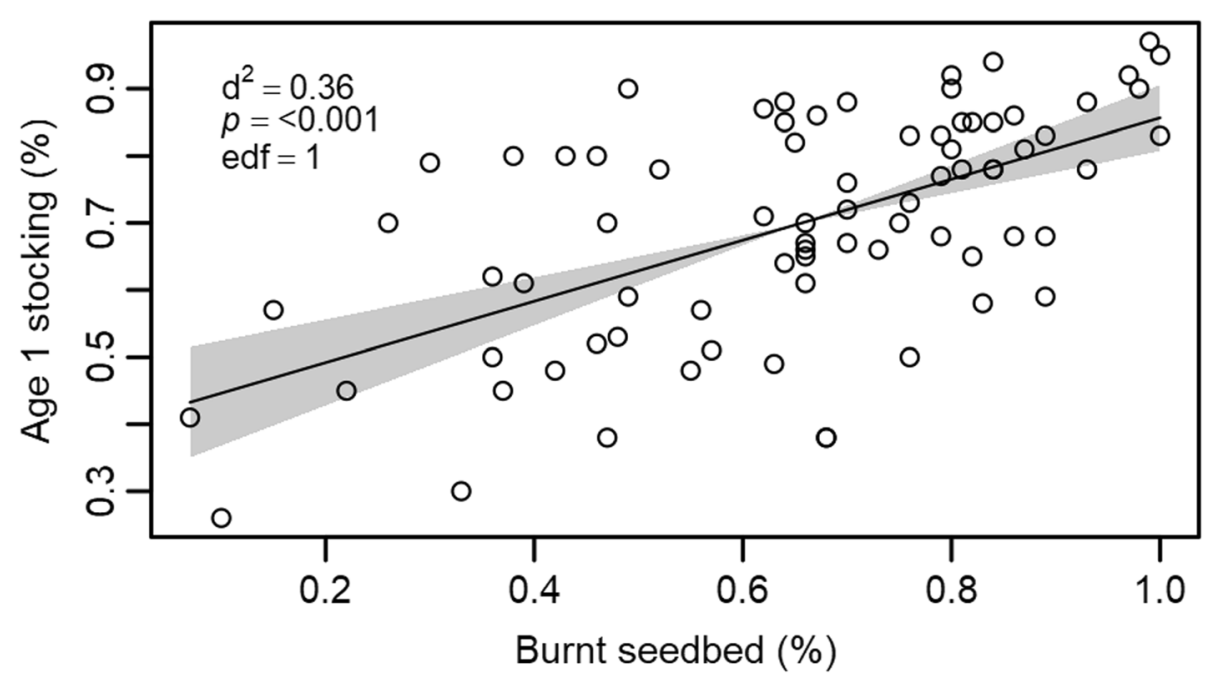

Fig. 8 Results of a generalized additive model of the relationship between eucalypt stocking at age 1 year and burnt seedbed in ARN coupes $(n=76)$. The model has simplified to a linear model (edf $=1)$. Shaded areas indicate the $95 \%$ confidence interval. $d^{2}$ is the proportion of the null deviance explained by the model. $p$ values indicate the approximate significance of the single smooth term, while edf is the estimated degrees of freedom for the smooth term

harvest of public native forest in Tasmania, and this proportion is likely to increase (M. McLarin, personal communication, 27 Feb. 2019). ARN will continue to play a significant role in the native forest harvesting program into the future, as Sustainable Timber Tasmania seeks to attain Forest Stewardship Council certification.

Over $90 \%$ of ARN coupes harvested in Tasmania have met the forest influence target of $>50 \%$, which is similar to the success rate reported in the initial stages of ARN implementation (Scott et al. 2015; Baker et al. 2017) and to that experienced during the implementation of variable retention harvesting in coastal British Columbia, Canada (Bunnell et al. 2009). The earliest ARN coupes were planned without the benefit of GIS tools for calculating influence levels; thus, it is not surprising that some of them missed the target. However, some more recent coupes have also failed to meet the target, which highlights the importance of continued monitoring of coupe outcomes and ongoing feedback and training for staff.

ARN coupes had, on average, $68 \%$ of the harvested area under forest influence, and influence levels were more than twice as high as comparable clearfells. This should ensure that ARN coupes follow a different trajectory of re-establishment and stand development when compared to clearfells (Baker et al. 2013b). Research in southern Tasmania has shown that proximity to nearby mature forest affects the microclimate and can accelerate the rate of successional recovery by plants and animals (Tabor et al. 2007; Baker et al. 2014, 2016; Hingston et al. 2014; Balmer 2015; Fountain-Jones et al. 2015). Regenerated areas with shaded microclimates and nearby retained mature forest had more mature forest-affiliated plants and animals. The distance that mature forest influence extended varied from approximately 15 to $200 \mathrm{~m}$, depending on the species of interest and time since harvest (Tabor et al. 2007; Hingston et al. 2014; Balmer 2015; Fountain-Jones et al. 2015; Baker et al. 2016).

Mean retention levels in Tasmanian ARN coupes have remained relatively stable over time at $\sim 30 \%$ and are high compared to retention levels in other temperate regions (Gustafsson et al. 2012). Similarly, with an average size of 1.3 ha for islands and 4.8 ha for edges, aggregates in Tasmania are generally much larger than elsewhere (Vanha-Majamaa and Jalonen 2001; Beese et al. 2003; Gustafsson et al. 2012). This is despite Tasmania not having a minimum retention target. Several coupes have been planned with no internal aggregates ( $0 \%$ retention) but with enough long-term retention immediately adjacent to the coupe to provide the required levels of influence and achieve the ecological objectives. These areas of long-term retention may include streamside reserves, wildlife habitat clumps, and other priority conservation habitats as well as areas excluded from harvesting for operational or economic reasons.

There have been significant changes to the type and number of aggregates retained, with edge aggregates making up an increasing proportion of retention in ARN coupes and fewer island aggregates retained. These changes have largely been made to facilitate regeneration burning in ARN coupes (Scott et al. 2012b). Although no increase in the proportion of burnt seedbed has been observed, the proportion of retained aggregates impacted by the burns has probably decreased (Scott et al. 2012b). These changes are also likely to reduce soil disturbance 
Table 2 Mean differences in selected variables between paired ARN and CBS coupes harvested from 2010 to 2018

\begin{tabular}{|c|c|c|c|c|c|c|c|}
\hline Variable & ARN mean & CBS mean & Mean difference (ARN-CBS) & Test used & Test statistic & Number & $p$ value \\
\hline \multicolumn{8}{|l|}{ Coupes harvested from 2010 to 2018} \\
\hline Perimeter (m) & 4506 & 3691 & 815 & Paired $t$ & 2.36 & 49 & 0.0226 \\
\hline Harvested area (ha) & 25.8 & 38.8 & -13.1 & Paired $t$ & -4.53 & 49 & $<.0001$ \\
\hline Perimeter-to-area ratio $\left(\mathrm{m} \mathrm{ha}^{-1}\right)$ & 186 & 108 & 77.9 & Paired $t$ & 9.9 & 49 & $<.0001$ \\
\hline Forest influence (\%) & 63 & 32 & 31 & Paired $t$ & 12.59 & 49 & 0.0035 \\
\hline Retention (\%) & 28 & 0 & 28 & Wilcoxon & 528 & 49 & $<.0001$ \\
\hline Burnt seedbed (\%) & 63 & 79 & -17 & Paired $t$ & -4.39 & 36 & $<.0001$ \\
\hline Stocking age 1 year (\%) & 68 & 77 & -9 & Paired $t$ & -2.71 & 35 & 0.0103 \\
\hline Density age 1 year (sph) & 2063 & 2682 & -696 & Paired $t$ & -2.58 & 34 & 0.0036 \\
\hline
\end{tabular}

Means for each silvicultural system are shown as well as the mean difference between the paired coupes (ARN-CBS). Tests used, test statistics, and $p$ values are shown, with significant differences indicated in italics

and compaction due to firebreaks (Scott et al. 2012a, 2012b), which can negatively impact both eucalypt stocking and growth and the native forest understorey plant community (Neyland et al. 2009; Hindrum et al. 2012). However, the reduction in both perimeter-to-area ratio and number of island aggregates may also make it more difficult to meet some of the other objectives of VR harvesting, such as maintaining a visual appearance that differs from clearfells (Scott and Baker 2018).

Burnt seedbed was lower in ARN coupes than in comparable CBS coupes by an average of $17 \%$ for coupes harvested between 2010 and 2018, which differs from earlier findings of no difference in seedbed conditions due to a silvicultural system (Scott et al. 2012b). These differences appear to be due to achieving better burns in the CBS coupes rather than poorer ones in the ARN coupes, as the amount of burnt seedbed in ARN coupes did not change significantly over time. The reasons for the improved burning outcomes in the CBS coupes are currently unknown but merit further exploration. It may also be worth looking more closely at burning methods and outcomes in ARN coupes to see if these could be improved.

Eucalypt seedling stocking and density were also significantly lower in ARN coupes than in comparable CBS coupes at age 1 year, reflecting the differences in the burnt seedbed. Again, this conflicts with earlier results which found no differences due to silvicultural system (Scott et al. 2013) but supports the findings of several other silviculture trials in Australia, which have found that alternative systems reduced stocking and density or survival and growth when compared to clearfells (Bassett and White 2001; Lutze and Faunt 2006; Neyland et al. 2009). There were strong positive linear relationships between burnt seedbed and seedling stocking and density at age 1, supporting previous studies that have found that eucalypt regeneration success is closely linked to the creation of well-burnt seedbed (Neyland et al. 2009; Scott et al. 2013). Burning also stimulates germination of numerous vascular plant species with soil-stored seed and thus has ecological as well as silvicultural benefits (Hindrum et al. 2012).

Table 3 Mean differences in selected variables between paired ARN and CBS coupes harvested from 2003 to 2009, shown for comparison with recent results

\begin{tabular}{|c|c|c|c|c|c|c|c|}
\hline Variable & ARN mean & CBS mean & Mean difference (ARN-CBS) & Test used & Test statistic & Number & $p$ value \\
\hline \multicolumn{8}{|l|}{ Coupes harvested from 2003 to 2009} \\
\hline Perimeter (m) & 4642 & 2836 & 1806 & Paired $t$ & 5.12 & 31 & $<.0001$ \\
\hline Harvested area (ha) & 20.7 & 28.5 & -7.7 & Paired $t$ & -2.5 & 31 & 0.0175 \\
\hline Perimeter-to-area ratio $\left(\mathrm{m} \mathrm{ha}^{-1}\right)$ & 224 & 127 & 97.5 & Wilcoxon & 465 & 31 & $<.0001$ \\
\hline Forest influence (\%) & 73 & 33 & 41 & Paired $t$ & 8.66 & 31 & $<.0001$ \\
\hline Retention (\%) & 30 & 0 & 30 & Wilcoxon & 378 & 31 & $<.0001$ \\
\hline Burnt seedbed (\%) & 63 & 68 & -6 & Paired $t$ & -2.04 & 31 & $0.025^{*}$ \\
\hline Stocking age 1 year (\%) & 69 & 69 & -0.5 & Paired $t$ & -0.14 & 31 & 0.445 \\
\hline Density age 1 year (sph) & 3633 & 3083 & 550 & Wilcoxon & 259 & 31 & 0.42 \\
\hline
\end{tabular}

Means for each silvicultural system are shown as well as the mean difference between the paired coupes (ARN-CBS). Tests used, test statistics, and $p$ values are shown, with significant difference indicated in italics. Reprinted from Scott et al. (2012b) and Scott et al. (2013), with permission from Elsevier, and from Scott et al. (2015), with permission from Taylor \& Francis (https://www.tandfonline.com/)

*One-tailed $p$ 
Successfully implementing regeneration burns remains the primary challenge of implementing aggregated retention harvesting in Tasmania. Conventional high-intensity burning occurs in the autumn, before the winter rains set in but while fuels are still dry. Climatic conditions and likely smoke impacts on nearby communities constrain the number of burns that can be conducted, with the government issuing a limited number of "smoke units" for proposed burns. In ARN coupes, conventional high-intensity burns cannot be used due to the risk of burning island aggregates and an alternative approach (slow burning) is applied. This type of burning carries a higher risk than conventional burns, as it requires specific weather conditions and very dry fuels and relies on fires self-extinguishing along the edges of the coupe (Chuter 2007). Fuels are likely to burn less completely but for longer, which may increase the production of smoke and increase the risk of escapes, and require additional resources to monitor these fires and ensure that they are extinguished (Forestry Tasmania 2009a). These issues all combine to limit the area that can feasibly be harvested and regenerated using ARN each year (Forestry Tasmania 2009a).

The implementation of aggregated retention in Tasmania has been shaped by the unique ecological, political, and social context within which Tasmanian forestry is practiced, but provides lessons that can be applied in other areas. High levels of existing forest reservation have resulted in a focus on forest influence rather than retention levels for distinguishing variable retention from clearcutting. The need for broadcast burning has encouraged a shift towards the use of edge aggregates rather than islands. These practices evolved in recognition that proximity of high-quality retention to harvested areas was a key ecological criterion determining biodiversity outcomes, and that this could be achieved with external areas designated as long-term retention if the size and shape of harvested areas permitted, and if these areas consist of high-quality habitat. Many regions use island aggregates as a means of visually distinguishing variable retention from conventional harvesting, but since there may be greater integrity of retained habitat in edge aggregates, wider application of this approach in other regions could be worthwhile.

\section{Conclusions}

Despite a decade of tumultuous change in the Tasmanian forest industry, aggregated retention is now firmly embedded as a viable alternative to clearfell, burn and sow for wet eucalypt forests. Twenty years ago, this was not considered possible, especially given the challenges surrounding regeneration burning. However, both burning outcomes and early regeneration in ARN coupes have been acceptable, indicating that silvicultural objectives can be met in variable retention coupes, at least in the short term. There is also clear evidence that variable retention provides biodiversity and ecological benefits when compared to clearfelling (Tabor et al. 2007; Baker and Read 2011; Baker et al. 2009, 2016; Balmer 2015; Gates et al. 2009; Lefort and Grove 2009; Stephens et al. 2012). Based on 16 years of ecological and silvicultural research, combined with monitoring and adaptive management of operations, there is a solid evidence base for the merits and achievability of ARN, providing strong support for the continuing use of variable retention in these forests.

\section{Acknowledgements \\ Data and support for this study were provided by Sustainable Timber Tasmania. Comments from three anonymous reviewers greatly improved the manuscript. We would like to thank the many people who have contributed to the development, implementation, and monitoring of variable retention harvesting in Tasmania over the past 16 years. There are too many of you to mention individually, but your contributions are greatly appreciated.}

\section{Funding}

Not applicable

Availability of data and materials

The datasets used and/or analyzed during the current study are available from the corresponding author on reasonable request.

\section{Authors' contributions \\ RS collated, analyzed, and interpreted the data and was a major contributor to the manuscript. MN and SB made substantial contributions to the conception and design of the work and to the interpretation of the data and revised the manuscript. All authors read and approved the manuscript.}

Ethics approval and consent to participate

Not applicable

Consent for publication

Not applicable

\section{Competing interests}

The authors declare that they have no competing interests.

\section{Publisher's Note}

Springer Nature remains neutral with regard to jurisdictional claims in published maps and institutional affiliations.

\section{Author details}

1Sustainable Timber Tasmania, 99 Bathurst St, Hobart, Tasmania 7001, Australia. ${ }^{2}$ School of Natural Sciences and ARC Centre for Forest Value, University of Tasmania, Private Bag 55, Hobart, Tasmania 7001, Australia.

Received: 14 March 2019 Accepted: 7 May 2019

Published online: 14 June 2019

\section{References}

Aubry KB, Halpern CB, Peterson CE (2009) Variable-retention harvests in the Pacific Northwest: a review of short-term findings from the DEMO study. For Ecol Manag 258:398-408 https://doi.org/10.1016/j.foreco.2009.03.013

Baker SC, Garandel M, Deltombe M, Neyland MG (2013a) Factors influencing initial vascular plant seedling composition following either aggregated retention harvesting and regeneration burning or burning of unharvested forest. For Ecol Manag 306:192-201 https://doi.org/10.1016/j.foreco.2013.06.027

Baker SC, Grove SJ, Forster L, Bonham KJ, Bashford D (2009) Short-term responses of ground-active beetles to alternative silvicultural systems in the Warra Silvicultural Systems Trial, Tasmania, Australia. For Ecol Manag 258:444-459 https://doi.org/10.1016/j.foreco.2009.03.044 
Baker SC, Grove SJ, Wardlaw TJ, McElwee DJ, Neyland MG, Scott RE, Read SM (2017) Monitoring the implementation of variable retention silviculture in wet eucalypt forest: a key element of successful adaptive management. For Ecol Manag 394:27-41. https://doi.org/10.1016/j.foreco.2017.03.013

Baker SC, Read SM (2011) Variable retention silviculture in Tasmania's wet forests: ecological rationale, adaptive management and synthesis of biodiversity benefits. Aust For 74:218-232

Baker SC, Spies TA, Wardlaw TJ, Balmer J, Franklin JF, Jordan GJ (2013b) The harvested side of edges: effect of retained forests on the re-establishment of biodiversity in adjacent harvested areas. For Ecol Manag 302:107-121

Baker TP, Baker SC, Dalton PJ, Fountain-Jones NM, Jordan GJ (2016) Temporal persistence of edge effects on bryophytes within harvested forests. For Ecol Manag 375:223-229

Baker TP, Jordan GJ, Steel EA, Fountain-Jones NM, Wardlaw TJ, Baker SC (2014) Microclimate through space and time: microclimatic variation at the edge of regeneration forests over daily, yearly and decadal time scales. For Ecol Manag 334:174-184

Balmer J (2015) Floristic response to landscape context in vascular plant communities in Eucalyptus obliqua and Eucalyptus regnans wet forest, southern Tasmania. PhD thesis, School of Land and Food. University of Tasmania

Bassett OD, White G (2001) Review of the impact of retained overwood trees on stand productivity. Aust For 64:57-63. https://doi.org/10.1080/00049158.2001.10676162

Beese WJ, Zielke K, Bancroft B (2003) Maintaining attributes of oldgrowth forests in coastal B.C. through variable retention. For Chron 79:570-578

Bunnell FL, Dunsworth GB, Beese WJ (2009) Implementing the approach. In: Bunnell FL, Dunsworth GB (eds) Forestry and biodiversity: learning how to sustain biodiversity in managed forests. UBC Press, Vancouver

Chuter R (2007) Feasibility of burning debris from wet eucalypt forests harvested to an aggregated retention prescription. Forestry Tasmania, Hobart

Fedrowitz K, Koricheva J, Baker SC, Lindenmayer DB, Palik B, Rosenvald R, Beese WJ, Franklin JF, Kouki J, Macdonald E, Messier C, Sverdrup-Thygeson A, Gustafsson L (2014) REVIEW: can retention forestry help conserve biodiversity? A meta-analysis. J Appl Ecol 51:1669-1679

Forestry Tasmania (2005) High intensity prescribed burning. Forestry Tasmania, Hobart

Forestry Tasmania (2009a) A new silviculture for Tasmania's public forests: a review of the variable retention program. Forestry Tasmania, Hobart https:// www.sttas.com.au/sites/default/files/media/documents/science/ anewsilviculturewebversion.pdf

Forestry Tasmania (2009b) Lowland wet eucalypt forests. Forestry Tasmania, Hobart https://www.sttas.com.au/sites/default/files/media/documents/ science/technical-bulletins/tb8weteucalypts.pdf

Forestry Tasmania (2010) Silvicultural systems for native eucalypt forests, Hobart https://www.sttas.com.au/sites/default/files/media/documents/science/ technical-bulletins/tb5silvsystems.pdf

Forestry Tasmania (2012) Regeneration surveys and stocking standards. Forestry Tasmania, Hobart https://www.sttas.com.au/sites/default/files/media/ documents/science/technical-bulletins/tb6regensurveys.pdf

Fountain-Jones NM, Jordan GJ, Baker TP, Balmer J, Wardlaw TJ, Baker SC (2015) Living near the edge: being close to mature forest increases the rate of succession in beetle communities. Ecol Appl 25:800-811

FPA (2017) State of the forests Tasmania 2017. Forest Practices Authority, Hobart

Franklin J, Berg D, Thornburgh D, Tappeiner J (1997) Alternative silvicultural approaches to timber harvesting: variable retention harvest systems. In: Creating a forestry for the 21 st century: the science of ecosystem management. Island Press, Washington, DC, pp 111-139

Gates G, Ratkowsky D, Grove S (2009) Aggregated retention and macrofungi: a case study from the Warra LTER site, Tasmania. Tasforests 18:33-54

Gustafsson L, Baker SC, Bauhus J, Beese WJ, Brodie A, Kouki J, Lindenmayer DB, Lohmus A, Pastur GM, Messier C, Neyland M, Palik B, Sverdrup-Thygeson A, Volney WJA, Wayne A, Franklin JF (2012) Retention forestry to maintain multifunctional forests: a world perspective. BioScience 62:633-645

Hindrum L, Hovenden MJ, Neyland MG, Baker SC (2012) The effects of mechanical disturbance and burn intensity on the floristic composition of two-year old aggregated retention coupes in Tasmanian wet eucalypt forests. For Ecol Manag 279:55-65 https://doi.org/10.1016/j.foreco.2012.05.003

Hingston AB, Jordan GJ, Wardlaw TJ, Baker SC (2014) Bird assemblages in Tasmanian clearcuts are influenced by the age of eucalypt regeneration but not by distance from mature forest. Glob Ecol Conserv 2:138-147

King M, Cook J (1992) The regeneration of Eucalyptus regnans under alternative silvicutural systems. 2. Seedbed descriptions (1st season replicate). Department of Conservation and Natural Resources, Victoria
Lefort P, Grove S (2009) Early responses of birds to clearfelling and its alternatives in lowland wet eucalypt forest in Tasmania, Australia. For Ecol Manag 258: 460-471 https://doi.org/10.1016/j.foreco.2009.04.022

Lindenmayer D, Franklin J, Lõhmus A et al (2012) A major shift to the retention approach for forestry can help resolve some global forest sustainability issues. Conserv Lett 5:421-431

Lutze M, Faunt KA (2006) The East Gippsland Silvicultural Systems Project. III: site occupancy, species composition and growth to 12 years. Aust For 69:198-212

Mitchell S, Beese W (2002) The retention system: reconciling variable retention with the principles of silvicultural systems. For Chron 78:397-403

Mori AS, Kitagawa R (2014) Retention forestry as a major paradigm for safeguarding forest biodiversity in productive landscapes: a global metaanalysis. Biol Conserv 175:65-73 https://doi.org/10.1016/j.biocon.2014.04.016

Neyland M, Hickey J, Beadle C, Bauhus J, Davidson N, Edwards L (2009) An examination of stocking and early growth in the Warra silvicultural systems trial confirms the importance of a burnt seedbed for vigorous regeneration in Eucalyptus obliqua forest. For Ecol Manag 258:481-494

Neyland M, Hickey J, Read SM (2012) A synthesis of outcomes from the Warra Silvicultural Systems Trial, Tasmania, Australia: safety, timber production, economics, biodiversity, silviculture and social acceptability. Aust For 75:147-162

R Core Development Team (2018) R: a language and environment for statistical computing. R Foundation for Statistical Computing, Vienna

Rosenvald R, Lõhmus A (2008) For what, when, and where is green-tree retention better than clear-cutting? A review of the biodiversity aspects. For Ecol Manag 255:1-15 https://doi.org/10.1016/j.foreco.2007.09.016

Schirmer J, Mylek M, Magnusson A, Yabsley B, Morison J (2018) Socio-economic impacts of the forest industry: Tasmania. University of Canberra, Canberra https://www.fwpa.com.au/images/OtherReports/Socio_economic_impacts_ of_the_forest_industry_TAS.pdf

Scott RE (2008) VR influence calculator user manual version 1.1. Forestry Tasmania, Hobart

Scott RE, Baker SC (2018) Variable retention manual 2.0. Sustainable Timber Tasmania, Hobart

Scott RE, Hovenden M, Neyland M, Mitchell SJ, Adams PR, Wood MJ (2012a) Shortterm effects of firebreaks on seedling growth, nutrient concentrations and soil strength in southern Australian wet eucalypt forests. For Ecol Manag 278:110-117

Scott RE, Neyland MG, Hovenden MJ (2015) Variable-retention harvesting in Tasmania: regeneration success? Aust For 78:232-242. https://doi.org/10. 1080/00049158.2015.1077693

Scott RE, Neyland MG, McElwee DJ (2013) Early regeneration results following aggregated retention harvesting of wet eucalypt forests in Tasmania, Australia. For Ecol Manag 302:254-263. https://doi.org/10.1016/j.foreco.2013.03.005

Scott RE, Neyland MG, McElwee DJ, Baker SC (2012b) Burning outcomes following aggregated retention harvesting in old-growth wet eucalypt forests. For Ecol Manag 276:165-173. https://doi.org/10.1016/j.foreco.2012.03.026

Stephens HC, Baker SC, Potts BM, Munks SA, Stephens D, O'Reilly-Wapstra JM (2012) Short-term responses of native rodents to aggregated retention in old growth wet Eucalyptus forests. For Ecol Manag 267:18-27 https://doi.org/10. 1016/j.foreco.2011.11.037

Stone MG (1998) Forest-type mapping by photo-interpretation: a multi-purpose base for Tasmania's forest management. Tasforests 10:15-32

Tabor J, Hickey J, Wood J, McElhinny C (2007) Colonisation of clearfelled coupes by rainforest tree species from mature mixed forest edges, Tasmania, Australia. For Ecol Manag 240:13-23. https://doi.org/10.1016/j.foreco.2006.11.021

Sustainable Timber Tasmania (2018) Forest management plan. Sustainable Timber Tasmania, Hobart

Vanha-Majamaa I, Jalonen J (2001) Green tree retention in Fennoscandian forestry. Scand J For Res 16:79-90. https://doi.org/10.1080/028275801300004433

Wells P. Hickey JE (1999) Wet sclerophyll, mixed and swamp forest. In: Reid JB, Hill RS, Brown MJ, Hovenden MJ (eds) Vegetation of Tasmania. Australian Biological Resources Study, Hobart, pp 224-243

Wood SN (2017) Generalized additive models: an introduction with R, 2nd edn. Chapman and Hall/CRC, New York

Work TT, Shorthouse DP, Spence JR, Volney WJA, Langor D (2004) Stand composition and structure of the boreal mixedwood and epigaeic arthropods of the Ecosystem Management Emulating Natural Disturbance (EMEND) landbase in northwestern Alberta. Can J For Res 34:417-430. https://doi.org/10.1139/×03-238 